\section{Learning from Pandemics Past and Present for Service Theory and Practice}

Learning from Pandemics

\section{Editorial}

Like the years 1918-20, the years 2020-21 will be remembered as the time of a global health crisis. In light of the COVID-19 pandemic, the Journal of Service Theory and Practice (JSTP) issued a call for papers to understand such crises and their implications for service organisations, especially for their marketing activities. Although still ongoing, the COVID19 pandemic has already substantially affected humans across all sectors and occupations throughout the world. It poses unprecedented challenges for businesses, requiring continuous adjustment of their goals and practices. Both businesses and consumers have been forced to alter many long-standing habits and choices because of the fundamental safety measures adopted around the world, such as physical distancing, self-isolation, contact tracing and compulsory use of face masks to reduce the risk of infection.

This special issue (SI) identifies policies that were and/or should be put into place starting from the outbreak of the COVID-19 pandemic and also focuses on the responsibilities taken on by service providers and individual consumers. Why should services research study the effects of a pandemic? Living through a pandemic represents a transitional experience, as both consumers and companies need to adapt to rapid and profound changes. A transitional experience can be both positive and negative, and previous research suggests that some transitional experiences represent a source of positive change in individuals because they are encouraged to be more productive, creative and reflective (Bamber et al, 2017). However, pandemics also represent a difficult transition for many people, particularly vulnerable consumer groups such as the homeless, indigenous and addicts who find their basic care needs adversely affected. Faced with this complex situation, we believe that service research stands to gain from understanding the many divergent transitional experiences arising during a global pandemic.

The four manuscripts published in this issue consider pandemics as transformational periods and combine to describe both the unique challenges of a pandemic as well as offering unique opportunities for both businesses and individuals to rethink how they operate. The manuscripts in this SI focus on service businesses (Mele et al, 2021), lean service implementation (Tortorella et al, 2021), health care services (Brodie et al, 2021) and service to marginalized groups of people (Finsterwalder et al, 2021).

The first article, by Mele et al. (2021), entitled "The impact of coronavirus on business: Developing service research agenda for the post-corona world," represents a good starting point for the special issue, because the authors set a goal of identifying all business-related topics relevant to the pandemic discussed within an interested population in social media. In order to accomplish this, the authors scraped all posts related to "business" in a subdivision of the "reddit" social media site that was created specifically to discuss the impact of the COVID-19 coronavirus on businesses. Next, the authors used artificial intelligence (AI) software to analyze the resulting $(200,000+)$ posts, thereby identifying four key themes that they propose as potentially fruitful for investigation by service researchers. These resulting themes are: essential service provision, bricolage service innovation, responsible shopping practices and market shaping amid crisis.

Following up on the four key research themes identified would especially assist vulnerable consumers who are suffering due to the coronavirus. Such follow-up should consider the perspective taken, major concepts to be investigated and methods most suited to capture data.

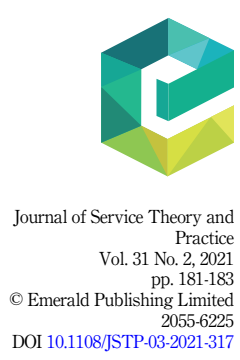


JSTP

31,2

182
The first of the identified themes redefines "essential" services and describes the culture and technology needed to provide them. For instance, Mele et al. (2021) note that governmental policy decisions affect service providers because their industries must be labeled "essential" in order to continue to operate. The second theme suggests the importance of innovating to better utilize (scarce) resources through changes to processes and outcomes. Because crises offer unique opportunities for change, the authors indicate that service innovation can be used in a transformational role. The third theme identifies responsible service practices, especially in retail settings. In this case, policy may be set by retailers, rather than by the government. Particularly when consumers shop in person, it is important to identify what it means for them to be "responsible" during the pandemic. Finally, the fourth theme offers insights regarding dealing with shocks. It mentions the importance of identifying which personal behaviors of both service providers and customers should be limited or encouraged.

In the second article, Tortorella et al. (2021) offer a managerial viewpoint of the pandemic, examining how the COVID-19 pandemic impacts the relationship between lean service implementation and performance. Contrary to what might be expected, the authors' findings indicate that the pandemic actually enhances this relationship. They consider supply chain issues, including both technical (e.g. tools) and social (i.e. people-related) aspects; a particular area of interest is the impact of the widespread switch to working from home. Tortorella et al. (2021) examine their hypothesis by conducting a survey among leaders of service organizations in India, as one of the countries with the most cases of COVID-19 in 2020. All of the respondents were working remotely and have been implementing lean for at least two years. Interestingly, the findings suggest that although having adopted lean management is helpful during the pandemic, this does not indicate that social distancing impacts the relationship between lean services implementation and organizational performance. However, a lesson for managers from the current pandemic is that organizations with more extensive adoption of lean practices might be spared the negative impact on performance experienced by others in the 'new normal' that the pandemic has brought.

Brodie et al. (2021) examine the management of health care during the COVID-19 pandemic through a service ecosystem perspective. This conceptual article identifies ways of alleviating some difficulties of health care provision. In particular, the authors argue that their perspective supports managerial flexibility, innovation, learning and knowledge sharing. These important issues were identified through a case study in Australia; one interesting observation made is that shocks to the system, such as that of the pandemic, offer the opportunity for improvements that would not have occurred otherwise. Brodie et al. (2021) also propose that having a shared world-view and institutional practices benefit a healthcare system in times of crisis. The article concludes with three propositions for future research, including: (1) highly indeterminate crises with widespread effects require complex solutions, (2) resources skilfully combined can cocreate positive well-being and overcome adverse outcomes and (3) uncertainty triggers supportive and disruptive actions that enable complementarity in practices.

The final article is a conceptual piece, recognizing the difficulties of vulnerable groups by focusing on the conditions of refugees during the COVID-19 pandemic (Finsterwalder et al. 2021). The authors detail a consumer point of view, taking a transformative service research perspective to argue that refugees are especially vulnerable consumers during a crisis such as a pandemic. Their reasoning is that refugees are less likely than other consumers to have lowerorder needs met, and hence, they are more likely to suffer in terms of physical, social and psychological well-being. In summary, Finsterwalder et al. (2021) express overwhelming concern that as there is a greater need for health care during a pandemic, it is less available for refugees to access. In order to deal with the potential risks of exclusion, the authors propose recognizing that refugees can provide resources as well as utilize them. Thus, the authors conclude that more inclusive and hospitable service systems will be of value to both refugees and service providers. 
This SI was heavily subscribed, and each guest editor was responsible for an equal number of submissions. All papers published in this SI have gone through at least two rounds of reviews and revisions, and two reviewers per submission provided valuable and constructive feedback.

As SI guest co-editors, we are grateful to a number of anonymous reviewers for their help in improving the accepted articles. We would like to thank Chatura Ranaweera and Marianna Sigala, the editors of the Journal of Service Theory and Practice, for encouraging us to initiate a dedicated special issue on this topic. We hope that the articles in this issue will stimulate more research developing new learnings for service theory and practice during pandemics and other crises.

\author{
Laszlo Sajtos \\ Marketing, The University of Auckland, Auckland, New Zealand \\ Liliana Bove \\ Management and Marketing, The University of Melbourne, Melbourne, Australia \\ Eileen Bridges \\ Marketing, Kent State University, Kent, Ohio, USA, and \\ Jonas Holmqvist \\ Department of Marketing, Kedge Business School Bordeaux, Talence, France
}

\title{
References
}

Bamber, M., Allen-Collinson, J. and McCormack, J. (2017), "Occupational limbo, transitional liminality and permanent liminality: new conceptual distinctions", Human Relations, Vol. 70 No. 12, pp. 1514-1537, doi: 10.1177/0018726717706535.

Brodie, R., Ranjan, K., Verreynne, M., Jiang, Y. and Previte, J. (2021), "Coronavirus crisis and healthcare: learning from a service ecosystem perspective", Journal of Service Theory and Practice.

Finsterwalder, J., Kabadayi, S., Fisk, R. and Boenigk, S. (2021), "Creating hospitable service systems for refugees during a pandemic: leveraging resources for service inclusion”, Journal of Service Theory and Practice.

Mele, C., Russo-Spena, T. and Kaartemo, V. (2021), "The impact of coronavirus on business: developing service research agenda for the post-corona world", Journal of Service Theory and Practice.

Tortorella, G., Narayanamurthy, G., Godinho, F.M., Portioli, S.A. and MacCawley, A. (2021), "Pandemic's effect on the relationship between lean implementation and services performance", Journal of Service Theory and Practice. 